Mirjana M. Pavlović*

Univerzitet u Beogradu

Filološki fakultet

Katedra za orijentalistiku

\title{
MELANHOLIČNI KINEZ U JAPANU: JU DAFUOVO „POTONUĆE"**
}

\author{
Originalni naučni rad \\ UDC 821.581.09-3 Dafu J. \\ $32(510)+32(520)$ \\ https://doi.org/10.18485/kkonline.2021.12.12.11
}

Za vreme pokreta Četvrtog maja (五四运动) Ju Dafu (郁达夫, 1896-1945) je bio izuzetno važna i uticajna figura na kineskoj književnoj sceni, kao i najznačajniji prozni pisac romantizma u Kini. Pod uticajem zapadne književnosti, ali i japanskog književnog žanra šišōsecu (私小説), u svojoj ranoj prozi stvorio je nezaboravan lik "suvišnog čoveka" - melanholičnog, osetljivog i usamljenog mladića, koga razdiru seksualne želje i koji, suočen s velikim društvenim i kulturnim promenama, nije u stanju da se uklopi u društvo.

U ovom radu, analizom Ju Dafuove novele „Potonuće” (沉沦，1921) pokušaćemo da ispitamo krizu ličnog i nacionalnog identiteta mladih kineskih intelektualaca tokom njihovog boravka u Japanu u politički osetljivom periodu kinesko-japanskih odnosa. U radu ćemo se dotaći i uticaja koji je japanska literarna forma šišōsecu imala na Ju Dafuovu prozu kako bismo ukazali na moderne književne elemente koje je ovaj pisaca uneo u svoje stvaralaštvo, što mu je donelo reputaciju jednog od najavangardnijih onovremenih književnika. šišōsecu

Ključne reči: melanholija, japansko-kineski odnosi, nacionalna kriza, kriza identiteta,

Dvadesetih godina minulog veka u jeku stvaranja kineske modernosti, Ju Dafu ( 郁达夫,1896-1945) se, kao jedan od osnivača romantičarski opredeljenog književnog društva "Stvaralaštvo" (创造社) ${ }^{1}$, istakao kao najznačajniji prozni pisac romantizma u Kini. Bio je prilično ekscentrična osoba hirovitog ponašanja, ali i stvaralac sklon dubokoj introspekciji i opsednut pitanjem moralne odgovornosti koju intelektualac treba da ima u društvu. ${ }^{2} \mathrm{U}$ svojoj prozi, bremenitoj autobiografskim detaljima, "s jednakom strašću bavio se emotivnim i seksualnim frustracijama pojedinca i

\footnotetext{
*Filološki fakultet u Beogradu, Studentski trg 3, 11000 Beograd, Srbija; e-mail: mirjanapav@beotel.net, mirjana.pavlovic@fil.bg.ac.rs.

** Početne ideje ovog rada izložene su u usmenom saopštenju na međunarodnoj konferenciji "Studije japanologije - Tradicija i izazovi budućnosti", održanoj na Filološkom fakultetu u Beogradu 18. novembra 2016. godine.

1 Društvo su 1921. godine u Tokiju osnovali kineski studenti koji su studirali u Japanu. U početku su objavljivali sopstvena dela, ali su vrlo brzo počeli da se bave i kritikom i promovisanjem romantizma preko prevoda zapadne romantičarske književnosti. Više o tome v. Pavlović 2004: 253-254.

${ }^{2}$ O Ju Dafuovom turbulentnom životu više videti u Lee 1973: 81-108 i Suzuki 2000.
} 
patriotskim osećanjima" (Pavlović \& Skrobanović 2014: 14), što je bila novina u kineskoj književnosti. ${ }^{3}$

Ju Dafuova prva zbirka novela Potonuće (沉沦，1921) ujedno predstavlja i prvu zbirku priča u modernoj kineskoj književnosti napisanu na govornom jeziku. Pored naslovne novele, u njoj su sabrane i priče "Odlazak na jug" (南迁) i "Srebrnosiva smrt” (银灰色的死). Kada je oktobra 1921. godine objavljena u Šangaju, u okviru novoosnovane književne edicije društva "Stvaralaštvo", knjiga je uzdrmala kinesku literarnu scenu i izazvala niz nepovoljnih kritika. Dok su konzervativci, s jedne strane, smatrali da su Ju Dafuove priče po sadržaju "nemoralne" (Zhou 1985: 1), i pojedini zagovornici nove književnosti (新文学), s druge strane, nisu isprva uviđali njihov književni značaj (Chen 2013: 13). Tek s prikazom koji je 26. marta 1922. godine u "Dodatku Jutarnjih novina" (晨报副镌) objavio Džou Cuožen (周作人，1885-1967)，jedan od najuticajnijih esejista, pisaca i prevodilaca pokreta Četvrtog maja (五四运动), ${ }^{4}$ nastaje preokret u vrednovanju Potonuća.

Pozivajući se na knjigu Erotski motiv u književnosti (The Erotic Motive in Literature) Alberta Mordela (Albert Mordell, 1885-1965), Džou ističe da, uprkos pojedinim lascivnim opisima, u Potonuću nema ničeg nemoralnog, te se u tom smislu ne razlikuje mnogo od drugih naturalističkih i dekadentnih proznih dela u kojima se ispituje nesvesno koje je usko vezano za seksualne porive (Zhou 1985: 2). Tu je, prema njegovom mišljenju, reč o "umetničkom delu, ali i o "književnosti za upućene ( 受戒者的文学, Literature for the initiated)" (Zhou 1985: 4). On dalje ističe "da je u zbirci opisana patnja savremenog mladog čoveka, čiji izvor leži u sukobu između volje za životom i stvarnosti. Pošto smo nezadovoljni stvarnošću, ali ne želimo ni da se prepustimo praznini, ne preostaje nam ništa drugo do da u ovoj teškoj i hladnoj stvarnosti i dalje tragamo za radošću i srećom koje ne možemo dosegnuti. Upravo po tome se tuga modernog čoveka razlikuje od tuge romantičnog doba" (Zhou 1985: 3). Džou Cuožen je očigledno smatrao da je patnja junaka Potonuća univerzalna, to jest da je ne osećaju samo protagonisti tih novela ili pisac, koji je u svoju prozu utkao niz ličnih osećanja, već i mnogi drugi intelektualci tog doba. Frustracije opisane u Ju

\footnotetext{
3 Denton ističe da je Ju Dafu opisom "seksualne frustracije, srama, depresije i mentalne nestabilnosti ponudio svež uvid u svet koji do tada nije bio istražen" (1992: 108).

4 Pokret Četvrtog maja kao antitradicionalni pokret, intelektualna revolucija i borba za promenu na društveno-političkom planu, u širem smislu trajao je od 1915. do 1925. godine. Više o tome na srpskom jeziku vidi u Pavlović 2004. Inače, Džou Cuožen je taj prikaz objavio pod književnim pseudonimom Džung Mi (仲密).
} 
Dafuovim pričama frustracije su čitave generacije koja traga za smislom i svrhom života u Kini oslabljenoj političkim nemirima i društvenim promenama. Upravo ta vrsta prepoznavanja u njegovom štivu doprinela je da knjiga, uprkos prvobitnim napadima, doživi veliki uspeh kako kod kritike tako i kod čitalaca, naročito mladih. ${ }^{5}$

Kakav je to duh vremena koji je Ju Dafu opisao u svojim pričama, u čemu konkretno leži koren „tuge modernog čoveka”, ali i koji su to novi narativni elementi utkani u njegovu prozu, zbog kojih je zadobio reputaciju jednog od najavangardnijih pisaca svoga doba? Pre nego što pokušamo da rasvetlimo ta pitanja, treba da imamo u vidu da je Ju Dafu zbirku Potonuće napisao za vreme svog devetogodišnjeg studijskog boravka u Japanu, ${ }^{6}$ gde je došao u dodir s mnogim delima zapadne književnosti i savremenim japanskim literarnim tokovima, te pod njihovim uticajem uneo moderne tematske i narativne elemente u sopstveno stvaralaštvo. ${ }^{7} \mathrm{U}$ ovom radu, analizom Ju Dafuove novele „Potonuće”, koja je njegova najpoznatija priča, ispitaćemo krizu identiteta mladih kineskih intelektualaca, kako na ličnom tako i na nacionalnom planu, za vreme njihovog boravka u Japanu u politički osetljivom periodu kineskojapanskih odnosa. Sem toga, ukazaćemo i na uticaj koji je japanska literarna forma šišōsecu (私小説) imala na Ju Dafuovo književno stvaralaštvo.

„Potonuće" je, dakle, priča o neimenovanom melanholičnom i preosetljivom mladom Kinezu koji studira u Japanu, ali koji nikako ne uspeva da se prilagodi novom društvenom miljeu. S vremenom, opterećen seksualnom žudnjom koju uspeva da zadovolji samo masturbiranjem, njegova melanholija prerasta u dublji oblik depresije i paranoje. Protagonista se sve više svojevoljno otuđuje od porodice - „zbog neke

\footnotetext{
5 Ovde je, doduše, zanimljivo primetiti da je Potonuće i pre nego što je Džou Cuožen na molbu sâmog Ju Dafua napisao prikaz već imalo tri izdanja, i to u periodu od samo mesec dana. U trenutku kada je poslao Džou Cuoženu razglednicu s molbom da mu pomogne, Ju Dafu taj podatak najverovatnije nije znao jer u to vreme nije živeo u Šangaju. U svakom slučaju, podrška znamenitog intelektualca za mladog književnika bila je vrlo značajna, što je Ju Dafu više puta isticao (Chen 2013: 18-19).

${ }^{6}$ Ju Dafu je 1913. godine otišao u Japan sa svojim starijim bratom, kojeg je nova kineska vlada poslala da prouči japansku sudsku administraciju. Naredne godine, kao državni stipendista, upisao se u pripremno odeljenje Prve više škole u Tokiju (东京第一高等学校), u početku na društveno-humanistički smer, a zatim se, najverovatnije po bratovljevom savetu, prebacio na medicinu. Posle završenog kursa, upisao se na smer prirodnih nauka Osme više škole u Nagoji (名古屋第八高等学校), ali se naredne godine ipak opredelio da studira političke nauke. Po završenim studijama, godine 1919. upisao je ekonomiju na Carskom univerzitetu u Tokiju (东京帝国大学), gde je diplomirao 1922. godine. Posle toga vratio se u Kinu (v. Lee 1973: 88; Guo 1983: 711-712).

7 Pre odlaska u Japan, Ju Dafu je pisao poeziju u tradicionalnom stilu, kojoj se i u poznijim godinama svoje karijere često vraćao. Li Ou-fan Li ističe da je među svojim savremenicima kineski pisac bio prilično jedinstvena pojava s obzirom na to da kao srednjoškolac uopšte nije čitao, u to vreme vrlo važne i popularne, Lin Šuove (林纾, 1852-1924) prevode dela zapadne književnosti smatrajući ih nižerazrednim. Stoga je "u periodu kada su se vremena menjala, a Kina nalazila u procesu ćudljive ,modernizacije', Ju Dafuov mentalni svet ostao tradicionalan" (Lee 1973: 87). Analizirajući Ju Dafuove rukopise, Čen Cišan navodi da je piščeva "žeđ za čitanjem proznih dela" stvorena upravo za vreme njegovog boravka u Japanu, kada je pročitao niz dela zapadnih književnika, prvenstveno ruskih i nemačkih, ali i japanskih modernih pisaca (Chen 2013: 8 i 9).
} 
gluposti" posvađao se sa starijim bratom, koji je oduvek bio zaštitnički i pokroviteljski raspoložen prema njemu, i „prekinuo svaki odnos s njim” (Ju 2014: 43). Otuđuje se i od svojih kineskih prijatelja s kojima je zajedno studirao, jer smatra da ga oni ne razumeju. S japanskim školskim drugovima, usled osećanja lične nesigurnosti ali i niže vrednosti zbog nacionalne pripadnosti, nikada se nije ni osmelio da ostvari prisniji kontakt. Japanskim ženama, koje su ga seksualno privlačile, tek se nije usuđivao da priđe. Između njega i ostatka sveta stvorio se, čini se, nepremostiv jaz. Protagonista utočište pokušava da pronađe u prirodi, ali na kraju ni tu ne nalazi utehu, jer, uprkos privremenom spokoju koji oseća kada šeta beskrajnim poljima, razdiruća usamljenost, posle niza samoponižavajućih radnji, kao što su voajerstvo, samozadovoljavanje, koje on smatra grehom, i alkohol, odvode ga ka očajničkom činu krajnje autodestrukcije kada će potražiti smrt u talasima okeana.

Espen Hamer u svojoj zanimljivoj studiji Unutarnji mrak: Esej o melanholiji ističe da su "strah i bezrazložna tuga na neki način nezaobilazni elementi, ako ne nužno i cela suština melanholije" (2009: 36). Te dve odlike melanholije jasno su izražene i u opisu duševnog raspoloženja glavnog junaka „Potonuća”. Strah protagoniste retko je izazvan nekim stvarnim razlogom, kao, na primer, u situaciji kada se našao u maltene pustom pansionu na periferiji grada N. Pa ipak, iako "sablastan predeo" i „zloslutni zvukovi” (Ju 2014: 34) mogu u junaku proizvesti bojazan od eventualne opasnosti, i ovde je više reč o strahu koji je proistekao prvenstveno iz njegovog osećanja nemira što je njegovo novo prebivalište, za razliku od rodne varošice "koja je vrvela od ljudi" (Ju 2014: 34) i mnogoljudnog Tokija u kom je prethodno živeo, krajnje izolovano. Jer, ukoliko se i u onom „nepreglednom moru ljudi” (Ju 2014: 34) u japanskoj prestonici junak osećao usamljeno, moglo se očekivati da će se u nenaseljenom mestu njegova zebnja samo povećati. Njegov strah je, međutim, najčešće uparen s dubokim osećanjem krivice zbog činjenice da nije u stanju da kontroliše svoje seksualne potrebe (Ju 2014: 36, 37 i 47), koje zadovoljava samo masturbiranjem i voajerstvom. ${ }^{8}$ I za tugu junak ponekad ima konkretan razlog, kao što je, na primer odlazak iz Tokija, zbog čega se oseća nostalgično, ali je ona pre svega opisana kao opšte stanje njegovog duha kome se ne zna uzrok i koja se manifestuje kao duboka melanholija gde je melanholični junak okrenut isključivo samom sebi, sopstvenim mislima i sopstvenim osećanjima. Upravo ta okrenutost samom sebi izazvala je i gubitak samopoštovanja, što se, prema Frojdu, „ispoljava kao prekor i samoizrugivanje” (1985: 121), čemu

\footnotetext{
${ }^{8}$ Lan ističe da koren junakovog osećanja krivice dok masturbira leži u tome što za njega taj čin predstavlja "narušavanje konfucijanskih predstava o svetosti tela i njegovoj svetoj upotrebi u širenju porodične linije" (2011: 122). O toj temi vidi i Chow 1991: 141-143.
} 
junak "Potonuća" u intimnim preispitivanjima svojih postupaka često pribegava. Osim straha i bezrazložne tuge, njemu se mogu pripisati i neka druga stanja, koja su nekada „bila klasifikovana kao melanholija, ali koja bismo mi danas sasvim jasno odvojili od melanholije" (Hamer 2009: 36), kao što su hipohondrija9 ${ }^{9}$ umor od života. Njegova mentalna iznurenost očitava se i na fizičkom planu, pa su mu, izmorenom strahom i izmučenom osećanjem krivice, „jagodice [...] bile izražajnije, crnosivi kolutovi oko očiju su se povećali, nekada živahne zenice sada su ličile na oči mrtve ribe" (Ju 2014: 37). Za Ju Dafua, kao i u slučaju mnogih zapadnih romantičarskih pisaca, melanholija je očigledno vrsta raspoloženja, ili, da se poslužimo Hajdegerovom terminologijom, štimunga (Stimmung), koja melanholiku pruža nov uvid u razumevanju sveta. ${ }^{10} \mathrm{U}$ "Potonuću", kao i u nekim kasnijim Ju Dafuovom pričama, taj nov uvid očitava se u tesnoj vezi između osujećenog libida i nacionalne pripadnosti.

Da bi se objasnila ta sprega između libidinalnog i nacionalnog, treba da imamo u vidu da su u vreme kada je pisana ova novela odnosi između Kine i Japana u političkom smislu bili napeti. Već u drugoj polovini XIX veka, a naročito posle ponižavajućeg poraza Kine u kinesko-japanskom ratu 1895. godine, Kina je bila primorana da shvati da je Japan postao napredna zemlja. S druge strane, i Japan više nije posmatrao Kinu kao kulturni uzor, štaviše, počeo je da je gleda s potcenjivanjem. Tako su „japanski političari, edukatori i predstavnici štampe počeli da izražavaju svoj prezir prema ,kineskim kukavicama' (chan-chan bózu)”, dok su „ideolozi u akademskim i političkim krugovima hvalili visok nivo japanske civilizacije a omalovažavali kinesku nazivajući je varvarskom" (Keaveney 2004: 11). S druge strane, u kineskom narodu, posebno od 1915. godine, zbog japanskih teritorijalnih pretenzija i širenja uticaja na teritoriji Kine, sve više jača antijapanski sentiment, koji će kulminirati 4. maja 1919. godine velikim demonstracijama na Trgu Tijenanmen u Pekingu, a zatim i širom zemlje protiv potpisivanja Versajskog ugovora prema kome je provincija Šandung trebalo da pripadne Japanu. Stoga su mnogi kineski intelektualci u ovom periodu, naročito oni koji su studirali u Japanu, prema toj zemlji gajili

\footnotetext{
${ }^{9}$ Hipohodnrija je u Juovoj priči shvaćena kao oblik depresije, a ne kao strah od umišljene bolesti. O upotrebi pojma hipohondrija u romantičarskoj književnosti uopšte, kao i u Ju Dafuovoj noveli detaljnije videti u Lan 2011: 109-114.

${ }_{10}$ Opisujući stanje melanholije, Hamer koristi Hajdegerov izraz štimung, što znači „,biti naštimovan, pre nego se eksplicitno orijentisati ka nečemu. [...] Pojedinci žive svoju melanholiju, ona ih okružuje, oni se kreću u njenom (tromom, bezbojnom) elementu, a da je za stalno ne ukorene u nekom određenom, namerno izabranom objektu (u konkretnoj oblasti značenja)" (2009: 18-19).
} 
ambivalentna osećanja. S jedne strane, nisu se slagali sa imperijalističkim ambicijama Japana, ali, s druge strane, divili su se njegovom napretku u modernizaciji društva. ${ }^{11}$

U tom kontekstu, u „Potonuću”, kao i u drugim Ju Dafuovim pričama čija je radnja smeštena u Japanu, uzrok seksualne frustracije poniženog i prezrenog mladog protagoniste direktno je povezan sa svešću o poniženoj i prezrenoj domovini. To je naročito očigledno u njegovom monologu koji sledi nakon što se prekoreo jer se zbog kukavičluka nije, poput trojice Japanaca koji su hodali pored njega, obratio japanskim studentkinjama „u crvenim suknjama”. Odmah potom pak nalazi i opravdanje za svoj postupak:

Kakav si ti tupan, ako ih neko i zanima, to sigurno nisi ti! Zar nisu njihovi pogledi bili upućeni samo onoj trojici Japanaca? Ah! Ah! One su već znale, već su znale da sam ja jedan kineski tupadžija ${ }^{12}$. Zašto, inače, nisu i mene pogledale?! Ima da im se osvetim, jednog dana ću im se osvetiti. (Ju 2014: 26)

Kada konačno skupi hrabrost da se zbliži s japanskim ženama, protagonista ulazi u javnu kuću, ali ni tu ne uspeva da se opusti, jer ga, na kelneričino pitanje odakle je, nanovo prevladava osećanje srama i stida:

Kad ču njeno pitanje, njegovo mršavo bledo lice opet se zajapurilo. Samo je nerazgovetno promucao nešto kao odgovor. Jadan on, opet je stajao na giljotini.

U stvari, Japanci preziru Kineze kao što mi preziremo pse. Nazivaju nas "kineskim tupadžijama”, a to u Japanu zvuči još ružnije nego kad mi za nekog kažemo da je ništarija. I sada, pred devojkom lepom kao cvet, mogao je samo da prizna: „Da, ja sam kineski tupadžija.”

"Kino, ah, Kino, zašto ne ojačaš?!" (Ju 2014: 50)

Prvo seksualno iskustvo može biti traumatično i u uobičajenim okolnostima, ali za protagonistu "Potonuća” dodatna nevolja očigledno leži u tome što taj čin treba da ostvari s devojkom druge nacije, i to nacije koja, uopšteno govoreći, gaji prezir prema

\footnotetext{
${ }_{11}$ Više o kinesko-japanskim odnosima u tom kontekstu vidi Keaveney 2004 i 2009. O konkretnim istorijskim detaljima vidi Renuven 1965.

12 U kineskom originalu stoji izraz Džinažen (支那人), stari naziv za Kineze koji vodi poreklo iz staroindijskih budističkih tekstova (sanskritska transliteracija naziva dinastije Ćin), a u Japanu se češće koristio od perioda Meiđi (明治時代, 1868-1912) do 1945. godine. Krajem XIX veka, međutim, taj izraz poprimio je derogativnu konotaciju, mada prvenstveno u očima Kineza. Detaljnije o poreklu, značenju i upotrebi tog naziva videti u Fogel 1995: 66-76 i 2015: 24-46. Fogel ističe da su negativne konotacije ovog naziva bile vezane za prljavštinu, nesposobnost, lenjost, slabost (2015: 39).
} 
Kinezima. "S jedne strane”, kako je primetila Ši Šumei, „potiskivanje njegove želje može se opravdati patriotizmom, jer su objekat njegove želje Japanke. S druge strane, on oseća da ga sve Japanke, čak i prostitutke, preziru, tako da potiskivanje postaje stanje egzistencije" (Shih 2001: 117). U tom kontekstu, jasno je da je "slabost nacije uslovila simboličku kastraciju kineskog muškarca" (Shih 2001: 116).

$\mathrm{Na}$ ovom mestu, međutim, treba ukazati i na to da melanholija protagoniste nije otpočela u Japanu, ona je u toj zemlji samo uzela maha. Ju Dafuov junak je i tokom svog života u Kini pokazivao znake nestalnosti i nesposobnosti da se fokusira na određeni cilj u životu - više puta je menjao škole, dolazio u sukob s najbližima i sa širom okolinom; iako ushićen novim saznanjima koja može dobiti iz knjiga, on je retko u stanju da pročita jednu knjigu od početka do kraja. Njegova melanholija zapravo počinje u trenutku kada se, nezadovoljan školskim programima i nastavnicima, kako u kineskim, tako i u misionarskim školama, i nesposoban da se „povinuje konvencijama” (Ju 2014: 28) „jer je bio čovek koji je voleo slobodu” (Ju 2014: 29), vraća kući u svoju malenu radnu sobu. Izolovavši se od svih, on se predaje fantazijama u kojima sebe vidi "kao osećajnog viteza, dve kćeri udovice iz komšiluka kao potomkinje plemića, a svoj zavičaj pretvorio je u idilično mesto" (Ju 2014: 30). Koliko god to zvučalo paradoksalno, ta vrsta fantaziranja, shvaćena kao želja da se bude ono što nismo, jedan je od prvih znakova da Ju Dafuov junak podsvesno shvata da nije dorastao zadatku koji mu postavljaju porodica i konfucijanska tradicija - da bude odgovoran, vredan i trezven student kako bi postao koristan član društva. Otuda i njegovo osećanje stida i srama, koje će se intenzivirati tokom njegovog boravka u Japanu.

Oblikujući lik glavnog junaka u "Potonuću”, Ju Dafu je imao u vidu zapadnu romantičarsku prozu i u prvom redu lik "suvišnog čoveka" iz Turgenjevljevih romana, ${ }^{13}$ dakle neprilagođenog individualca koji usled raspada društvenog poretka nije u stanju da realizuje svoj potencijal i uklopi se u društvo. Zbog toga se oseća promašeno i neispunjeno, te postaje "suvišan”. Pa ipak, koliko god su u rasvetljavanju problema "suvišnosti" spoljni faktori važni, toliko se pažljivo moraju ispitati i lične slabosti pojedinca. Protagonista "Potonuća”, naime, vrlo često ima iskrivljenu percepciju realnosti, drugih ljudi i svog mesta u svetu. O tome vrlo rečito svedoči njegov, isprva trivijalan, sukob s bratom s kojim će na kraju preko pisma prekinuti odnos:

\footnotetext{
13 Osim u ovoj noveli, na lik "suvišnog čoveka” nailazimo i u drugim Ju Dafuovim delima. Štaviše, jednu od svojih kasnijih priča nazvao je "Suvišan čovek" (零余者, 1924). O Ju Dafuovim književnim vezama s ruskom književnošću vidi $\mathrm{Ng}$ 1988: 83-128, a o njegovom liku "suvišnog čoveka” vidi i u Wen 1980: 232-239, Xu 1985: 220-228. U literaturi se često navode i literarne paralele između Ju Dafua i drugih zapadnih romantičarskih pisaca kao što su Bajron, Gete (videti Lee 1973) ili Ruso (videti Xu 1985: 201-206).
} 
Kad je poslao pismo, odsutno je seo na travnjak ispred kuće i dugo razmišljao. Za sebe je mislio da je najnesrećniji čovek na svetu. A u stvari, taj razdor sam je započeo. Interne razmirice prerasle su u porodičnu svađu i od tada je mrzeo svog najstarijeg brata kao što se mrzi najcrnji neprijatelj. Kad bi ga neko kinjio, on bi to svaki put uporedio s primerom svoga brata:

"Šta očekivati od drugih ljudi kad se i tvoj rođeni brat tako ponaša?!"

Kad god bi došao do tog zaključka, do sitnih detalja bi se prisećao grubog načina na koji se brat poneo prema njemu. Pošto bi nabrojao sve ono što se desilo u prošlosti, presudio bi da je njegov najstariji brat rđav čovek, a on dobar. (Ju 2014: 43-44, kurziv autorke teksta)

Iako je, prema sopstvenom priznanju, sam započeo svađu, pa se može pretpostaviti da je u velikoj meri lično kriv za razdor sa inače dobronamernim bratom, glavni junak „Potonuća” gotovo opsesivno i mazohistički uporno pokušava da iz tog sukoba izađe kao pobednik. Sličnih primera u kojima protagonista pokušava da opravda svoje ponašanje u ovoj noveli ima dosta, poput, na primer, i gorenavedene scene u kojoj prekoreva samog sebe posle susreta sa dvema Japankama, koje su, zapravo, najverovatnije bile voljne da stupe u razgovor ne samo s japanskim studentima, nego i s njim. U prvi mah, on je svestan da uzrok njegove nemuštosti leži u njemu samom, u sopstvenoj nesigurnosti, kao i u strahu od neuspeha, naročito u odnosu na druge muškarce, ali da bi stekao unutarnji mir, svoj „kukavičluk” vrlo brzo pripisuje slabosti svoje domovine. Uopšteno govoreći, način na koji Ju Dafuov junak pravda svoje postupke i uspostavlja duševnu ravnotežu, čini nam se, u izvesnoj meri predstavlja rafiniraniju verziju psihološkog mehanizma pomoću kojeg $A$ Kju, karikaturalni lik koji epitomizuje tipičnog Kineza na početku XX veka u čuvenoj Lu Sjunovoj (鲁迅, 1881-1936) noveli „Istinita priča o A Kjuu” (阿Q正传), objavljenoj posle Ju Dafuove priče, odnosi svoje „psihološke pobede”. ${ }^{14}$ Dok, međutim, Lu Sjunovog neukog i neosvešćenog junaka nagon za samoodržanjem gura napred, pa se nekakav pomak u njegovom životu, koliko god on bio postignut neprihvatljivim metodama, može videti, Ju Dafuov protagonista sve više „tone” u mračni lavirint svoje duše. Najzad, u svom monologu na kraju priče, koji izgovara neposredno pre odlaska u smrt,

\footnotetext{
${ }^{14}$ Novela „Istinita priča o A Kjuu” prvobitno je izlazila u pekinškom „Dodatku Jutarnjih novina” (晨报副刊) u nastavcima od 4. decembra 1921. godine do 12. februara 1922, a kasnije je sabrana u Lu Sjunovoj prvoj zbirci pripovedaka Poklič (呐喊, 1923). To je pripovest o neobrazovanom nadničaru koji ide kroz život tako što zavaravajući sebe pokušava da zavara i druge. Prevod na srpski jezik sadržan je u zbirci Poziv na oružje (Lu Hsin 1977).
} 
junak još jednom svoju sudbinu neraskidivo vezuje za sudbinu čitave nacije, te svu odgovornost za sopstvene neuspehe svaljuje na slabu državu, gotovo patetično zahtevajući od domovine da se obogati i ojača. Sa stanovišta psihološke analize, međutim, traženje "krivca”" na drugoj strani tipično je ponašanje čoveka s kompleksom niže vrednosti koji, pozivajući se na loše stanje u zemlji, svom činu samoubistva pokušava da pripiše viši značaj (Pavlović \& Skrobanović 2014: 14). Imajući to u vidu i uprkos činjenici da "Potonuće" u velikoj meri sažima mnoge probleme svog vremena u borbi za razvoj ličnosti, slažemo se sa Li Ou-fan Lijem kada kaže da je Ju Dafuov nacionalizam više lične i psihološke prirode nego samo političke i ideološke (Lee 1973: 91).

Gradeći lik kineskog „suvišnog čoveka”, Ju Dafu nije bio samo pod uticajem zapadne književnosti. Istraživači su ukazali na izrazito bliske i očigledne veze između japanske narativne forme šišōsecu i Ju Dafuove proze, (Itō 1985; Wen 1980; Keaveney 2004 i 2009; Radtke 2014). Te paralele ne treba da čude, naročito ako se uzme u obzir da je šišōsecu tipično japanski pripovedni žanr koji se razvio u periodu Taišo (大正時代, 1912-1926), ${ }^{15}$ dakle u vreme kada je Ju Dafu studirao u Japanu gde se vrlo dobro upoznao sa savremenom japanskom književnom scenom i gde je imao priliku da razmeni iskustva s japanskim piscima. Savremeni japanski pisac kome se kineski književnik izuzetno divio bio je Satō Haruo (佐藤春夫, 1892-1964), jedan od najvažnijih predstavnika te vrste proze, s kojim se sprijateljio 1922. godine i u kome je, bar na početku svog književnog stvaralaštva, video mentora. ${ }^{16}$

Sličnosti između Ju Dafuove novele "Potonuće", kao i nekih drugih priča iz njegovog ranog stvaralaštva, i romaneskne forme šišōsecu mogu se analizirati najmanje iz dva ugla, i to prvenstveno sa stanovišta narativne forme, a potom i u pogledu teme.

Pođimo od prvog aspekta. Šišōsecu je vrsta ispovedne proze u kojoj su, iako se u njoj najčešće pripoveda u trećem licu, opisana iskustva ili raspoloženje samog pisca. Događaji u romanima tog tipa najčešće su fiktivni, ali narativni tok obiluje mnogim autoreferencijalnim detaljima. ${ }^{17}$ I zaista, u gotovo svim Ju Dafuovim pričama

\footnotetext{
15 Taj žanr je nikao iz naturalističke škole perioda Meiđi (Keaveney 2004: 21).

16 Satō je sa suprugom 1927. godine posetio Šangaj i tom prilikom Ju Dafu im je bio vodič. Ta poseta, smatraju istraživači, obeležila je vrhunac njihovog prijateljstva. Krajem tridesetih godina prošlog veka, međutim, njihovo prijateljstvo se zbog političkih razmimoilaženja prekinulo. Više o njihovom prijateljstvu i književnim vezama videti u Keaveney 2009: 117-128.

17 Šišosecu ili vatakuši šosecu, u zavisnosti od toga kako se čita prvi karakter (ši u značenju "ličan", „privatan” i vatakaši u značenju „ja”) često se prevodi kao ja-roman (po uzoru na nemački Ich-Roman) ili roman o sebi. Više o nazivu tog žanra videti u Fowler 1988: 3-5, a o žanru uopšte videti u Fowler 1988, Keaveney 2004: 17-28.
} 
uočava se "piščeva senka” (Wen 1980: 240), bilo da je reč o biografskim sličnostima između pisca i njegovih junaka, ili o "sopstvenom duhovnom razvoju, gde je sve opisano iz njegovog subjektivnog ugla” (Průšek 1969: 69). U "Potonuću”, kao i u šišōsecuu, radnja je svedena i jednostavna, ispričana u fragmentima, i u njoj gotovo ne postoji dramski sukob. Pisac je, dakle, usredsređen na protagonistu u priči, to jest događaji su ispričani iz njegovog ugla, dok su ostali likovi nerazvijeni. Povremeni i kratki dijalozi između glavnog i sporednih likova uglavnom služe kao okidač protagonisti da potvrdi ili razvije svoje mišljenje o temi koja ga okupira. Takva pak narativna shema omogućava piscu upotrebu mnogobrojnih unutarnjih monologa kojima se dodatno pojašnjava psihološko stanje glavnog lika. Istovremeno, međutim, čitalac je lišen objektivnijeg uvida u njegovu celokupnu ličnost upravo zato što on nije predstavljen kroz odnos sa drugim likovima, pa glavni junak, uprkos opisima njegove duboke introspekcije i gotovo narcističke okrenutosti samog sebi, ostaje nedorečen. $\mathrm{S}$ druge strane, pošto se pripoveda u trećem licu, naratorov objektivni i distancirani ton, prema Iganu, služi kineskom piscu da stvori „ironičnu protivtežu koja podriva junakov sentimentalan pogled na sebe, naglasivši suštinsku besmislenost njegove slike o sebi" (Egan 1977: 312). Taj nov narativni glas koji Ju Dafu, po uzoru na šišōsecu, gradi već u svojoj prvoj priči predstavlja novinu u modernoj kineskoj književnosti i inovativan način da se predstavi ono što je subjektivno $i$ individualno, što je bio i imperativ u književnosti pokreta Četvrtog maja.

U pogledu teme, Ju Dafuovo "Potonuće” naročito se može uporediti sa Satō Haruovom novelom Dani melanholije na selu (田園の憂镍, 1918) ${ }^{18}$ o nervno rastrojenom neimenovanom protagonisti i propalom piscu, koji se sa suprugom i njihova dva psa i mačkom seli na selo kako bi pobegao od života u sivoj i prenaseljenoj prestonici. U oba dela osnovna tema je otuđenost i svojevoljna izopštenost iz društva, pri čemu oba pisca nastoje da proniknu u suštinu psihološkog poremećaja svojih protagonista koji su posledica njihove nesposobnosti da se zbliže sa okolinom. Stoga, i Satō i Ju Dafu često koriste, za ono vreme nove, psihijatrijske pojmove kao što su megalomanija ili hipohondrija, $i$ to neretko na engleskom ili na nemačkom jeziku. I jedan i drugi protagonista pokušavaju da pronađu utočište u prirodi, ali bezuspešno. U Satōovoj noveli, međutim, "gubitak identiteta, odsustvo smisla života nisu predstavljeni kao specifičan problem protagoniste", prema Radtkeu, "već im je data šira, filozofska, ako ne i religijska dimenzija" (2014: 92). Pokušavajući da rasvetli krizu

${ }^{18}$ Taj roman prvo je nazvan Bolna ruža (病める薔薇). Vrlo pronicljivu komparativnu analizu Satōovog romana i Ju Dafuove trilogije Potonuće napisao je Radtke 2014. 
identiteta mladog Kineza, Ju Dafu, za razliku od svog japanskog uzora, naglasak stavlja na podvojenost duše i tela u pokušaju protagoniste da zadovolji svoje seksualne i emotivne potrebe. Dok u Satōovoj noveli ne nalazimo erotske scene, u Juovoj ih ima nekolicina, $i$ to prilično eksplicitnih. $U$ tom pogledu i kada je reč o paralelama sa šišōsecuom, „Potonuće” pre možemo porediti sa pripovetkom Kataija Tajame (田山 花 袋，1872 -1930) "Futon" (蒲団，1907) ${ }^{19}$ u kojoj je otvoreno i krajnje ogoljeno opisana neprimerena požuda sredovečnog i u braku nezadovoljnog nastavnika prema svojoj mladoj učenici, iako japanski protagonista, za razliku od kineskog junaka, ne oseća kajanje i samoprekor zbog svojih seksualnih želja i erotskih fantazija. U svakom slučaju, zanimljivo je pomenuti da su i Juova i Kataijeva priča upravo zbog takvih sadržaja delovale šokantno na njihove savremenike. ${ }^{20}$

Ono po čemu se Ju Dafuova proza razlikuje od ostalih dela iz žanra šišōsecu svakako jeste pitanje odnosa pisca prema krupnim društveno-političkim problemima svoga doba. Većina pisaca žanra šišōsecu sebe je smatrala apolitičnim (Keaveney 2004: 117) i, s obzirom na to da su u periodu Taišo živeli u politički i ekonomski relativno stabilnom društvu, mogli su da se osame u svojoj kuli od slonovače, iako to „nužno ne mora da znači da pisci nisu svesni društvenih i drugih promena, ili da se takve promene ne ogledaju u njihovim delima" (Radtke 2014: 89). S druge strane, politički angažovani pisci pokreta Četvrtog maja živeli su u zemlji koja se nalazila na prekretnici, opterećena krutom konfucijanskom tradicijom i dubokim političkim previranjima, kako na unutrašnjem tako $i$ na spoljašnjem planu. Stoga je $i$ larpurlartistički orijentisani Ju Dafu u ispovednoj prozi video, u stvari, sredstvo za kritiku društva. U "Potonuću”, u kome se prvenstveno razobličavaju emotivno stanje i kriza ličnog identiteta mladog Kineza ipak je "učitana i svest o ,bolesnom društvu', kao vinovniku abnormalnog psihološkog stanja kineskih intelektualaca toga doba" (Pavlović \& Skrobanović 2014: 14).

Ju Dafuovu novela "Potonuće” jasno svedoči o peokupacijama modernih kineskih pisaca koji su, nadahnuti zapadnim muzama, ali i japanskim stvaraocima, pokušavali da pronađu nove vidove književnog izražavanja. Opisujući u ispovednom tonu najintimnije muške emocije otuđenog mladog Kineza, Ju Dafu duboko zadire u

\footnotetext{
19 Ta priča smatra se „prototipskim šišōšecuom” (Fowler 1988: xvi). Vidi i Itō 1980: 518.

${ }^{20}$ Ovde, doduše, treba imati u vidu da za razliku od klasičnih kineskih erotskih romana, kao što su, na primer, Šljivin cvet u vazi od zlata (金瓶梅) iz dinastije Ming (明朝, 1368-1644) ili Li Juova (李渔，1610-1680) Prostirka za telesnu molitvu (肉蒲团) iz dinastije Ćing (清朝, 1644-1912) u kojima su seksualne scene vrlo živopisno opisane, u Juovoj, kao i u Kataijevoj priči nema opisa samog seksualnog čina (do kojeg, uostalom, ni u jednoj priči nije ni došlo). Tu je pre reč o uticaju koji seksualne želje i fantazije imaju na psihološko stanje i ponašanje protagonista.
} 
važno pitanje kineske modernosti i mesta pojedinca u zemlji suočenoj $\mathrm{s}$ krahom tradicionalnih vrednosti i raspadom društvenog poretka. U Ju Dafuovoj projekciji, kriza identiteta pojedinca usko je vezana za opštu krizu nacije, pa izlečenje "bolesti" savremenog čoveka u velikoj meri zavisi od toga na koji način će on odgovoriti na probleme koje donosi moderno doba. Bilo da je reč o narativnoj tehnici ili o temi koju obrađuje, Ju Dafu se profilisao kao značajan avangardni književni stvaralac, koji do danas intrigira kako književne kritičare, tako i čitaoce.

\section{Literatura}

Chen Z. (2013). Chencui chunfeng - Zhuixun Yu Dafu ji qita. Beijing: Zhonghua shuju. [陈子善 (2013). 沉醉春风---追寻郁达夫及其他. 北京：中华书局]

Chow, R. (1991). Woman and Chinese Modernity: The Politics of Reading Between West and East. University of Minnesota Press.

Denton, K. (1992). The Distant Shore: Nationalism in Yu Dafu's "Sinking". Chinese Literature: Essays, Articles, Reviews (CLEAR), 14, 107-123.

Egan, M. (1977). Yu Dafu and the Transition to Modern Chinese Literature. In Goldman M. (ed.), Modern Chinese Literature in the May Fourth Era. (pp. 309-324). Cambridge, MA: Harvard University Press.

Fogel, J. (1995). The Cultural Dimension of Sino-Japanese Relations: Essays on the Nineteenth and Twentieth Centuries. New York: M. E. Sharpe.

Fogel, J. (2015). In Between China and Japan. Leiden: Brill.

Fowler, E. (1988). The Rhetoric of Confession - Shishosetsu in Early Twentieth-Century Japanese Fiction. Berkeley and Los Angeles: University of California Press.

Frojd, S. (1985). Žalost i melanholija. Delo, 8/9, 120-134.

Guo M. (1980). Lun Yu Dafu. Zaiyu Guo Moruo lun chuangzuo. Shanghai: Shanghai wenyi chubanshe. (di 711-720 ye). [ 郭沫若 (1980). 论郁达夫. 载于郭沫若论创作. ( 第711-720页).上海：上海文艺出版社.]

Hamer, E. (2009). Unutarnji mrak - Esej o melanholiji. Beograd: Geopoetika.

Itō, T. (1985). "Chenlun" lun. Zaiyu Yu Dafu yanjiu ziliao. Zaiyu Chen Z. he Wang Z. (bian), Yu Dafu yanjiuziliao. (di 511-521ye). Guangzhou: Huacheng chubanshe. [伊藤 虎丸（1985）.《沉沦》论. 载于陈子善和王自力（编），郁达夫研究资料.（第511521页）.广州：花城出版社] 
Ju, D. (2014). Potonuće. U M. Pavlović i Z. Skrobanović (prir.), Antologija moderne kineske priče. (str. 19-55). Beograd: Geopoetika.

Keaveney, C. T. (2004). The Subversive Self in Modern Chinese Literature: The Creation Society's Reinvention of the Japanese shishôsetsu. New York: Palgrave Macmillan.

Keaveney, C. T. (2009). Beyond Brushtalk: Sino-Japanese Literary Exchange in the Interwar Period. Hong Kong: Hong Kong University Press.

Lan, F. (2011). From the De-Based Literati to the Debased Intellectual: A Chinese Hypochondriac in Japan. Modern Chinese Literature and Culture, 23(1), 105-132.

Lee, L. (1973). The Romantic Generation of Modern Chinese Writers. Cambridge, Massachusetts: Harvard University Press.

Lu Hsin, Poziv na oružje. Beograd: Nolit, 1977.

Ng, M. (1988). The Russian Hero in Modern Chinese Fiction. New York: State University of New York Press.

Pavlović, M. (2004). Teorijska ishodišta moderne kineske književnosti 1898-1925. U R. Pušić (ur.), Tragovi. (str. 238-257). Beograd: Filološki fakultet.

Pavlović, M., \& Skrobanović, Z. (2014). Zlatno doba moderne kineske proze. U M. Pavlović i Z. Skrobanović (prir.), Antologija moderne kineske priče. (str. 9-17). Beograd: Geopoetika.

Průšek, J. (1969). Three Sketches of Chinese Literature. Prague: Oriental Institute in Academia.

Radtke, K. W. (2014). Chaos or Coherence? - Sato Haruo's Novel Denen no yùutsu and Yu Dafu's Trilogy Chenlun. In A. Boscaro, F. Gatti and M. Raveri (eds.), Rethinking Japan Vol 1.: Literature, Visual Arts \& Linguistics. London and New York: Routledge.

Renuven, P. (1965). Pitanje Dalekog Istoka 1840-1940. Beograd: Prosveta.

Satō, H. (1993). The Sick Rose: A Pastoral Elegy. Honolulu: University of Hawaii Press.

Shih, S. (2001). The Lure of the Modern: Writing Modernism in Semicolonial China, 1917-1937. Berkeley and Los Angeles: University of California Press.

Suzuki, M. (2000). Yu Dafu: Beijuxing de shidai zuojia. Guangxi jiaoyu chubanshe. [ 鈴木正夫 (2000). 郁达夫 : 悲剧性的时代作家. 广西教育出版社.]

Takai, K. (1981). The Quilt and Other Stories. Tokyo: Tokyo University Press. 
Wen, R. (1980). Lun Yudafu de xiaoshuo chuangzuo. Zhongguo xiandai wenxue congkan. 2, 223-246. Beijing: Beijing chubanshe. [温儒敏 （1980）. 论有达夫的小 说创作. 中国现代文学研究丛刊. 第二辑, 223-246页. 北京 : 北京出版社]

Xu, Z. (1985). Langmanzhuyi? Ganshangzhuyi? Lingyuzhe? Sixiaoshuo zuojia? - Yu Dafu yu waiguo wenxue. Zhongguo bijiao wenxue, 1, 200-232. [许子东 (1985). 浪漫主义? 感伤主义? 零余者? 私小说作家? - - 郁达夫与外国文学. 中国比较文学，1， 200-232.]

Zhou Z. (1985). Chenlun. Zaiyu Chen Z. he Wang Z. (bian), Yu Dafu yanjiuziliao. (di 1-5 ye). Guangzhou: Huacheng chubanshe. [周作人 (1985) . 沉沦. 载于陈子善和 王自力（编），郁达夫研究资料。（第1-5页）.广州：花城出版社]

\section{Summary}

\section{A MELANCHOLIC CHINESE IN JAPAN: YU DAFU'S "SINKING"}

During the New Culture Movement (新文化运动) Yu Dafu (郁达夫，1896-1945) was a very important and influential figure on the Chinese literary scene, and the most significant fiction writer of Romanticism in China. Influenced by both Western literature and the Japanese shishōsetsu (私小説) literary genre, in his early fiction he created an unforgettable character of a "superfluous man" - a melancholic, sensitive, lonely young man, tormented by his sexual desires and unable to fit into the society that has undergone tremendous cultural and social changes.

In this paper, through the analysis of Yu Dafu's novella "Sinking" (沉沦, 1921), we will try to explore the confusion of Japan-based young Chinese intellectuals about their personal and national identity, which climaxed during the politically sensitive period of Sino-Japanese relations. At the same time, the paper attempts to offer some insight into the influence of the Japanese literary form shishōsetsu on Yu Dafu's writing as a source of modern literary elements, thus gaining the reputation of one of the most avant-garde writers of his time.

Key Words: melancholy, Sino-Japanese relations, national crisis, identity confusion, Shishōsetsu 